\title{
PARTITIONING OF ALLOYING ELEMENTS IN A NICKEL BASE SUPERALLOY CONTAINING No AND MO : AN ATOM-PROBE STUDY
}

\author{
D. Blavette, A. Boste1 and M. Bouet \\ Laboratoire de Microscopie Ionique ${ }^{+}$, Faculté des Sciences de Rouen, \\ BP 67, 76130 Mont-Saint-Aignan, France
}

\begin{abstract}
Résumé - Une sonde atomique à temps de vol est utilisée pour déterminer la composition des différentes phases existant dans un superalliage à base nickel ainsi que les sites préférentiels des différents éléments dans la phase ordonnée $\gamma^{\prime}$.
\end{abstract}

Abstract - A time of flight atom-probe is used for determining phase composition in a nickel base superalloy and a tentative derivation of preferential sites occupied by solute elements in the ordered $\gamma^{\prime}$ phase is made.

\section{INTRODUCTION}

The microstructure of nickel superalloys consists essentially in a FCC solid solution $(\gamma)$ and finely dispersed oxdered precipitates ( $\left.\gamma^{\prime}\right)$ with composition based on the formula $(\mathrm{Ni}, X)_{3}(A I, Y)$. The creep strength of such alloys is known to be strongly dependent upon the particle size, volume fraction and composition (connected with the antiphase boundary energy) of the $\gamma^{\prime}$ coherent phase.

In this study the fine scale microstructure of a nickel base superalloy is investigated by means of an atom-probe in order to determine the partitioning of alloying elements between both $\gamma$ and $\gamma^{\prime}$ phases. An other question of interest is to find the preferential sites. (Ni or Al type) solute elements such as Mo, Nb... preferentially occupy in the $\gamma^{\prime}$ sublattice. From a quantitative compositionnal analysis of (001) superlattice planes it has been possible to derive some informations about the long range order existing in $\gamma^{\prime}$ phase $|1|$.

\section{EXPERIMENTAL}

The apparatus used in this study is a conventional atom-probe $|2|$. The instrument details are described elsewhere $|3|$. All experiments were performed with a minimum pulse fraction $\rho=\frac{V_{p}}{V_{o}}=0.2$ and an evaporation rate not too high. Indeed, a too low pulse fraction may lead, for a given evaporation rate (i.e for $V_{p}+V_{0}=C s t$ ), to a preferential evaporation of "low evaporation field" atoms at the $D$. C voltage (i.e between each evaporation pulse) and therefore to biased compositions.

In the particulary case of nickel base alloy (Ni, Cr, Al), hydrogen is known to chemisorb on $\mathrm{Ni}$ and consequently reduces its evaporation field $|4|$. As a result, $\mathrm{Ni}$ is found to preferentially evaporate, in agreement with a recent study of Ni AI system $|5|$.

Another crucial parameter is the evaporation rate which play a key role on "detection isotopic effects" $|6|$. Indeed when the averaged number of collected ions per

UA CNRS 808 . 
evaporation pulse ( $n>0.05$ ) become too large, a not negligeable proportion of atoms having the same $\frac{M}{n}$ ratio strikes simultaneously the detector. As no amplitude measurement of the detection signal is avalaible for deriving the number of ions striking the detector the number of collected ions of each nature becomes biased. In such conditions, concentration of major elements (Ni) will be the most affected and the effects will be more pronounced for atomic species having solely one isotope and charge state (i.e one peak in the mass spectrum).

These artifacts have particulary drastic effects when a plane by plane analysis is achieved. Indeed, as the size of the analysed plane shrinks, the evaporation rate accelerates in its central portion because of the increase in local field above individual atoms (step like behaviour of the integral ion flux curve). Hence, in order to maintain the ions flux to a reasonnable value (number of collected ions per second) a high pulse repetition rate is required. All experiments were carried out with $f=40 \mathrm{~Hz}$ and with $n<0.01$ for the plane by plane analyses.

\section{RESULTS AND DISCUSSION}

Figure 1 shows a FIM image which illustrates the fine scale microstructure of the superalloy. More than $50 \%$ of the material volume is occupied by precipitates from $300 \AA$ to $1,5 \mu$ in diameter. The corresponding mass spectrum of brightly imaged precipitates is given figure 2 .

In spite of number of isotope overlaps ( $\mathrm{Ni}-\mathrm{Nb}, \mathrm{Ni}-\mathrm{MO}$ ) it was possible to quantify $\mathrm{Nb}$ and Mo concentrations by means of $\mathrm{Ni}$ isotopes distribution ( $\left.N i_{62}\right)$. The corrected concentrations, averaged over more than 35000 ions are summarized and compared in table 1 to that obtained by chemical analysis of extracted precipitates. Both results are in reasonnable agreement.

Integral composition profile corresponding to the analysis of (001) planes of the $\gamma^{\prime}$ ordered phase are

given in figure 3. As expected for a $\mathrm{Ll}$, structure ( $\mathrm{Ni}_{3} \mathrm{Al}$ ) one find the alternation of Al rich planes (mixed planes formed with Both sites $I$, IT) with Ni rich planes (pur planes formed with sites II). It has been already shown $|1|$, $|7|$ that it was possible to derive from the averaged composition of both types of planes, some informations about the preferential sites occupied by the solute elements in $\gamma^{\prime}$ sublattice.

Eventhough some artifacts introduced for example by a preferential retention of some elements from one plane to the following may occur, the results obtained with the atom probe $|8|$ are in good agreement with those predicted in the litterature $|9|$. Although the site preference of a third element may be affected by the addition 


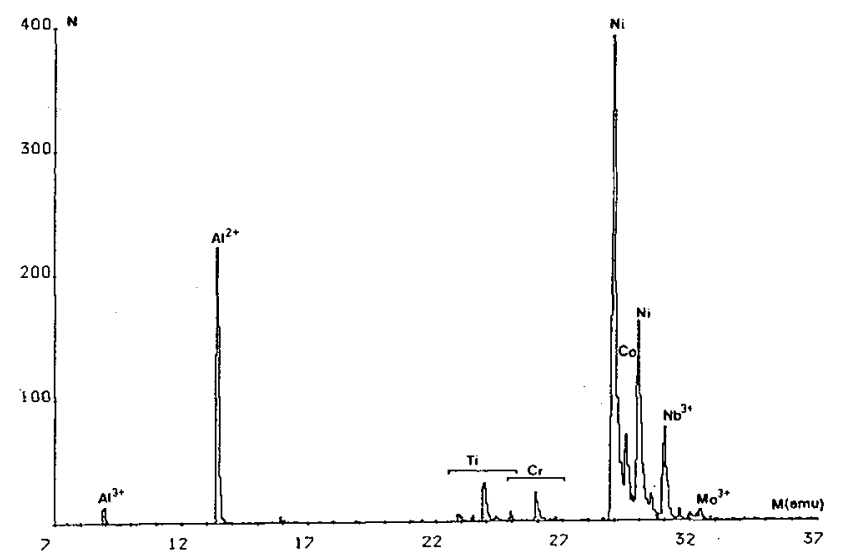

Fig. 2 - Atom probe mass spectrum relative to a primary precepitate

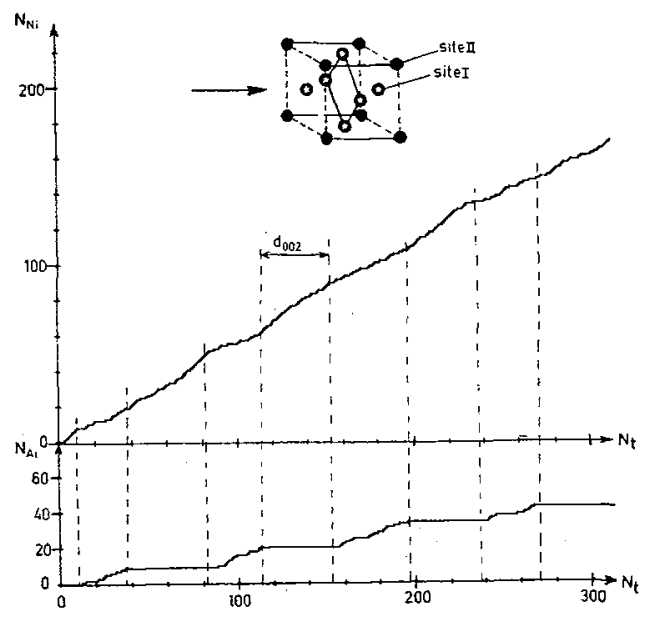

Fig. 3 - Analysis of $\gamma^{\prime}(001)$ superlattice planes. The cumulative number of $N i$ or $A l$ is plotted versus the number of identified ions.

of other elements in the $\mathrm{Ni}_{3} \mathrm{Al}$ phase, it is noticeable that the preferential sites suggested by the direction of solubility lobes in the ternary system $|10|$ are in reasonnable agreement with the atom-probe results: Mo, $\mathrm{Nb}, \mathrm{Ti}$ atoms preferentially occupy $A$ l sites while Co, Cr substitute $\mathrm{Ni}$.

Figure 4 shows the mass spectrum relative to a matrix analysis. Because of the good mass resolution, the seven isotopes of Mo are identifiable even in the plus three ionisation state. As the back ground noise is low, it is possible to distinguish a very little amount of Boron (0.09 at. \%). The chromium level was found higher than it was expected from $\gamma^{\prime}$ composition and the volume fraction of primary precipi- 
tates (50 vol \%) measured by chemical analysis. As a matter of fact, atom-probe analyses revealed the presence of very fine precipitates having a mean size varying from 30 to $100 \AA$. The integral composition profiles corresponding to a matrix analysis along an "analysis cylinder" having a diameter of $20 \AA$ is represented figure 5.

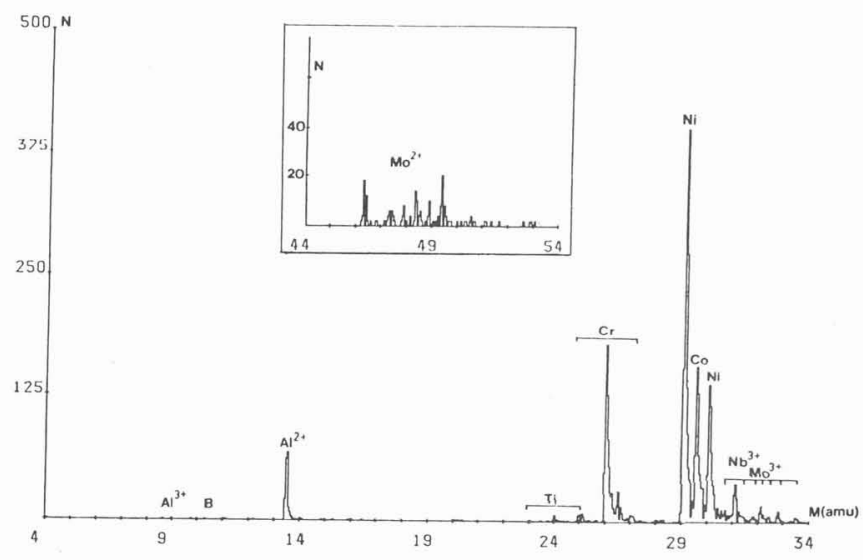

Fig. 4 - Atom-probe mass spectrum of matrix + secondary precipitates

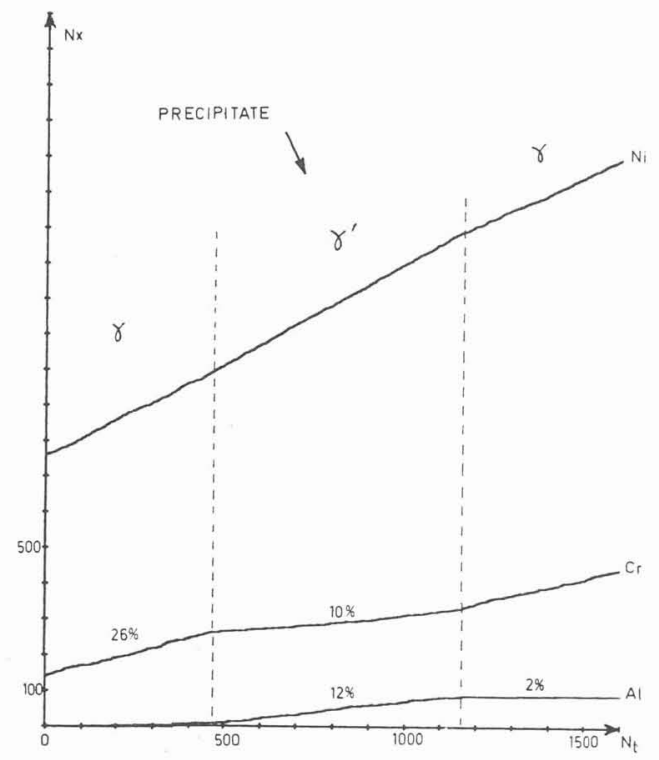

Fig. 5 - Integral composition profil corresponding to the matrix investigation. The cumulative number of $\mathrm{Ni}$ or $\mathrm{Cr}$ or $\mathrm{Al}$ is plotted against the cumulative number of identified ions 
One secondary precipitate was traversed and as indicated on the draw, its concentration is slightly different from that of primary precipitates. Obviously, such a difference could be due to a "mixed analysis" of the precipitate with its surrounded matrix as well. However, the profile slope changes very charply at the $\gamma-\gamma$ ' transition in such a way that this artifact is not thought to intervene here.

From various matrix analyses, it was possible to estimate the volume occupied by these secondaxy precipitates and to extract particles data traversed by the analysis cylinder in good conditions (i.e not on a edge). Averaged composition of these particles is given Table 1. From these data and the estimated volume fraction of secondary particles (10 vol. \%) one can compute a composition averaged over $\gamma$ matrix and secondary precipitates. This composition is compared in Table 2 to the "matrix" composition as deduced from nominal composition of the superalloy and primary $\gamma$ ' data (composition, volume fraction $=50 \%$ ). Both determinations are in good agreement and suggest that the very fine precipitates were dissolved during the extraction process, leading therefore to an underestimated volume fraction of $\gamma^{\prime}(50 \%$ instead of $60 \%)$.

\begin{tabular}{|l|c|c|c|c|c|c|c|}
\hline & $A 1$ & $T i$ & $C r$ & $N i$ & Co & Nb & Mo \\
\hline $\begin{array}{l}\text { Averaged atom-probe } \\
\text { data for } \gamma^{\prime} \text { phase } \\
\text { (at \%) }\end{array}$ & 13.85 & 4.33 & 2.14 & 66.62 & 5.83 & 5.56 & 1.38 \\
\hline $\begin{array}{l}\text { Statistical fluc- } \\
\text { tuations (at \%) }\end{array}$ & 0.18 & 0.1 & 0.07 & 0.25 & 0.12 & 0.12 & 0.06 \\
\hline $\begin{array}{l}\text { Chemical analysis } \\
\text { (at \%) }\end{array}$ & 13.52 & 4.53 & 1.89 & 66.67 & 6.22 & 5.88 & 1.29 \\
\hline $\begin{array}{l}\text { Secondary } \\
\text { precipitates }\end{array}$ & 11.7 & 1.7 & 8 & 65 & 6.3 & 4.1 & 3.3 \\
\hline $\begin{array}{l}\text { Statistical } \\
\text { fluctuations } 0\end{array}$ & 1 & 0.4 & 0.8 & 1.4 & 0.7 & 0.6 & 0.5 \\
\hline
\end{tabular}

Table 1 - Compositions of primary and secondary precipitates as measured by atom probe. Chemical analysis data are given for comparison

\begin{tabular}{|l|l|l|l|l|l|l|l|}
\hline & $A I$ & $T i$ & $C r$ & $N i$ & $C o$ & $N b$ & $M O$ \\
\hline $\begin{array}{l}\text { Atom-probe } \\
\text { data }\end{array}$ & 3.89 & 0.64 & 21.5 & 53.95 & 13.23 & 1.54 & 5.15 \\
\hline $\begin{array}{l}\text { Statistical } \\
\text { fluctuations }\end{array}$ & 0.3 & 0.11 & 0.4 & 0.6 & 0.35 & 0.15 & 0.25 \\
\hline $\begin{array}{l}\text { Chemical } \\
\text { analysis }\end{array}$ & 3.77 & 0.51 & 20.35 & 55 & 13.97 & 1.56 & 4.75 \\
\hline
\end{tabular}

Table 2 - Comparison of averaged composition of $\gamma+$ secondary precipitates, computed from atom probe data with the "matrix" composition as deduced by chemical analysis.

Acknowledgments

This study was performed in collaboration with the office National d'Etudes et de Recherches Aérospatiales (O.N.E. R. A. - Chatilion). The authors thank Drs $M$. MARTY and $A$. WALDER for the fruitful and stimulating discussions. 


\section{REFERENCES}

|1| D. BLAVETTE, A. BOSTEL, A. MENAND 30th I. F. E. S. - Philadelphia (1983) 116

|2| J. A. PANITZ Rev. SCi. Instr., 44 (1973) 1034

$13 \mid$ C. MARTIN - D. BLAVETTE - J. M. SARRAU Rev. Phys. Appl., 19 (1984) 27

$|4|$ M. WADA - R. VEMORI - O. NISHIKAWA Surf. Sci., 134 (1983) 17

|5| H. WENDT and P. HAASEN Acta Met., 31 (1983) 1649

$|6|$ T. T. TSONG - Y. S. NG - S. V. KRISHNASWAMY AppI. Phys. Lett., 32 (1978) 778

$|7|$ D. BLAVETTE - A. BOSTEL Acta Met., 32 (1984) 811

|8| D. BLAVETTE - A. MENAND Comptes rendus à I'Académie des sciences (1984)

$|9|$ M. MAGRINI - B. BADAN - E. RAMOUS

z. Metallkde, 74 (1983) 314

$|10|$ S. OCHTAI, Y. OYA - T. SUZUKI Acta Met., 32 (1984) 289 